Professora e pesquisadora da PUCRS. Atualmente desenvolve as seguintes pesergoló : Pica: questōes de linguagem e trabalho" (DI FANTI, 2014a) e "A tensa relacão com o discurso do outro e a producão de sentidos: contribuições bakhtinianas para a pesquisa e a formação na contemporaneidade" (Edital Pesquisador Gaúcho, FAPERGS, idem, 2014b). E-mail: gloria.difanti@pucrs.br

Doutoranda do Programa de Pós-Graduação em Letras da PUCRS, bolsista do CNPq. Desenvolve o projeto de doutorado "Uma voz apagada? Análise da atividade de revisão de textos acadêmicos sob as perspectivas bakhtiniana e ergologica" pesquisadores do projeto "A tensa relação com o discurso do outro e a produção de sentidos: contribuições bakhtinianas para a pesquisa e a formação na contemporaneidade", apoiado pela FAPERGS. E-mail: vanessa.barbosa@acad.pucrs.br

\title{
Uma entrevista com Yves Schwartz
}

\author{
Maria da Glória Corrêa di Fanti'1, Vanessa Fonseca Barbosa²
}

ntre os dias 24 e 30 de outubro de 2015, o professor, pesquisador, filósofo e ergólogo Yves Schwartz, da Aix-Marseille $\mathcal{U}$ Université - França, participou como visitante de várias atividades desenvolvidas pelo Programa de Pós-Graduação em Letras da Pontifícia Universidade Católica do Rio Grande do Sul (PUCRS). Além de ter proferido a palestra "Abordagem ergológica e necessidade de interfaces pluridisciplinares" no DUO VII (Dialogue Under Occupation), ministrou o curso intitulado "Ergologia: Trabalho e Produção de Saberes". Esse curso, organizado em parceria com o Programa de PósGraduação em Educação da Universidade Federal do do Rio Grande do Sul (UFRGS) e apoiado pelo CNPq, contou com a participação de professores e pesquisadores de diversas áreas do conhecimento de distintas universidades, que se interessam pela abordagem ergológica e pelos estudos da atividade de trabalho. Foram dias de intenso diálogo com o professor Schwartz que possibilitaram, dentre outros temas, refletir a respeito dos fundamentos da Ergologia, discorrer sobre seus conceitos-chave e suas questões éticas bem como tratar da relação entre os estudos ergológicos no Brasil e na França.

O intenso debate suscitou as perguntas desta entrevista, as quais foram gentilmente respondidas pelo professor Yves Schwartz e agora são compartilhadas com todos os leitores da Revista Letrônica. Aproveitamos a oportunidade para agradecer ao entrevistado pela disponibilidade e constante parceria ${ }^{1}$. Também gostaríamos de registrar nossos agradecimentos à Maria Serra - profissional inserida no mercado de trabalho e estudante de formação contínua do Conservatoire National des Arts et Métiers (CNAM), de Paris - que prontamente aceitou conduzir as perguntas e efetuar a gravação de nossa entrevista. Não temos dúvidas de que as reflexões aqui apresentadas muito podem contribuir para as pesquisas que se voltam para a análise de atividades humanas de trabalho a partir da abordagem ergológica.

${ }_{1}^{1}$ Parte da parceria está registrada brevemente no texto Linguagem e trabalho: diálogos entre estudos discursivos e ergológicos (DI FANTI, 2014c). 
1. Maria da Glória Corrêa di Fanti e Vanessa Fonseca Barbosa - Professor, na obra Trabalho e Ergologia: conversas sobre a atividade humana, há a afirmação de que a "Ergologia é a aprendizagem permanente dos debates de normas e de valores que renovam indefinidamente a atividade: é o 'desconforto intelectual'" (SCHWARTZ, DUC, DURRIVE, 2010, p. 30). Poderia nos falar um pouco mais sobre esse "desconforto intelectual"?

Yves Schwartz - Vou tentar. É verdade que essa atitude de desconforto intelectual é fundamental para a compreensão do nosso agir enquanto ergólogos. Acho que, desde a origem, quando era mais jovem, sentia um mal-estar, uma dificuldade oriunda da relação entre o que podemos chamar de saber acadêmico, saber universitário, o saber que tínhamos de difundir frente às vidas, às experiências, aos valores de nossos interlocutores, do mundo industrioso e do mundo do trabalho, como se fosse um descarte entre duas formas de saber, duas formas de reação ao saber, o que chamamos, esse sentimento, há muitos anos, como a existência de formas específicas de cultura e incultura. Começamos a nossa tese, defendida em 1986, por essa ideia de que, depois desses 15 anos de experiência, de contatos com o mundo industrioso e o mundo universitário, havia formas específicas de saberes formalizados, como dissemos depois, em desaderência com relação à vida real do trabalho. 0 mais específico desses saberes - que era uma forma de cultura, que tinha a sua nobreza, a necessidade do conceito, de poder desenvolver saberes conceitualizados - era uma dimensão essencial da vida humana, uma forma essencial de cultura, mas que, ao mesmo momento, nos conduzia a uma dificuldade de perceber outra forma de saber, outra relação com o mundo de valores, outra forma de cultura que emergia dentro do fazer industrioso. Ao mesmo tempo, essa forma específica de saber e de relação com o mundo de valores, desse mundo industrioso, poderia criar obstáculos à apropriação do outro mundo de cultura e de saber. Me parece que havia essa espécie de "cisão", de descarte, que era invisível, que era nociva tanto para o saber conceitual (em desaderência), quanto para o mundo industrioso. Isso cria um problema quase de democracia.

Para aprofundar essa questão, temos acompanhado os ergonomistas e sua maneira de aprender dos trabalhadores; parecia que cada vez na situação de trabalho - como não há só o saber mais ou menos em desaderência, o saber prescrito, o saber que eu chamo de normas antecedentes - sempre havia retrabalho, recomposição dessas normas, o que eu chamei, depois de alguns anos, renormalizações e que estão sempre frente a uma situação de trabalho. Tínhamos de ler uma espécie de mistura entre uma consequência em decorrência dos saberes das normas antecedentes, dos saberes em desaderência, e das renormalizações emergidas no trabalho. 0 resultado do trabalho era essa mistura.

1.1 E esse desconforto intelectual é o desconforto do trabalhador ou do universitário?

Yves Schwartz - Vou continuar. Boa pergunta. Cheguei a generalizar, a partir dessa atividade específica em que trabalharam os ergonomistas, e a definir não somente o trabalho, mas todo o agir humano como atividade, que é o conceito central da abordagem ergológica, a atividade sempre como um debate de normas. Eu falei de mistura, ou melhor, em um sentido dinâmico, de vai e vem permanente entre normas antecedentes e retrabalho/renormalização dessas normas. Isso quer dizer que sempre há uma espécie de debate entre esses dois polos e é uma necessidade antropológica que, sempre, frente a uma situação de trabalho ou a uma situação social, frente ao que foi antecipado ou prescrito (depende das 
situações), sempre há o pensamento fragilizado, posto em dificuldade, porque as renormalizações, individuais e coletivas, reduzem o valor do que foi antecipado como centro de valor, mas o nível que é posto em questão pelas renormalizações ninguém pode antecipar. Isso cria um desconforto intelectual para os que antecipam previamente o esquema do agir coletivo. Assim, se aceitarmos essa noção geral antropológica de atividade como debate de normas, a consequência é que aqueles que conceitualmente antecipam a atividade estão sempre em desconforto com relação ao que têm antecipado. Podemos dizer que esse desconforto é um desconforto intelectual e, por isso, olha, primeiramente, ao lado dos que construíram a antecipação, os que criaram as normas antecedentes com certo grau de desaderência em relação à atividade, a qual sempre vive na aderência do presente aqui e agora. É um desconforto intelectual, mas também podemos dizer que é um desconforto social ou ético, o que é uma outra questão, porque em qualquer renormalização há uma dimensão de valor, sempre há uma escolha; quando há um debate, há uma escolha, e uma escolha se opera com valores, por isso, chamo os saberes, que são a base da renormalização, como saberes-valores. Mas, por outro lado, há também um certo desconforto por parte do mundo dos trabalhadores face a conceitos gerais nos quais eles percebem uma pertinência relativa quanto à descrição de sua situação de vida e de trabalho, sem poder diagnosticar em que esses conceitos têm uma parte de inadequação em relação a eles. Para finalizar, com relação a essa questão, indico também a leitura do artigo Production de savoirs sur l'activité: quels nœuds entre Epistémologie et Ethique?, que saiu no número 14 da revista Ergologia no ano de 2015.

\section{Maria da Glória Corrêa di Fanti e Vanessa Fonseca Barbosa -} Na obra mencionada na questão anterior, o senhor afirma também que "A Ergologia constitui-se em um projeto de melhor conhecer e, sobretudo, de melhor intervir sobre as situações de trabalho para transformá-las" (ibidem, p. 37). Considerando as diversas maneiras das diferentes áreas intervir sobre as situações de trabalho, de que forma a Ergologia pode contribuir para a transformação da atividade de trabalho?

Yves Schwartz - É claro que, desde o início, a nossa ambição - desse grupo pequeno que começou a organizar uma formação acerca do trabalho, para trabalhar junto, sobre o que é trabalhar - era, a partir dessa iniciativa, contribuir para transformar positivamente, se for possível, o mundo do trabalho ${ }^{2}$. Esta ambição sempre foi o nosso ânimo: transformar as situações de trabalho. Como conceber essa contribuição é difícil de resumir em poucas palavras. Eu posso apresentar a pergunta assim: se aceitarmos essa situação que conduz ao desconforto intelectual, aceitaremos o fato de que, de um lado, há saberes mais ou menos codificados, mais ou menos em desaderência com o seu valor, mas também sempre mais ou menos a distância do agir da atividade; e, do outro lado, formas escuras de saberes ligados ou emergidos dentro do agir, não só do agir industrioso, mas de todo o agir. Se isso se disseminar, pode-se conceber uma relação, uma espécie de dialética entre esses dois polos, essas duas formas de saber.

Já falei das duas antecipações, a antecipação do saber do primeiro polo, do saber codificado, do saber em desaderência - que ocorre em toda a situação humana de vida, sobretudo em situações de trabalho - e que sempre antecipa o agir industrioso. A princípio são normas, referenciais de tarefas, organogramas, há uma quantidade de saberes registrados em 2 O grupo, formado pelo filósofo Yves Schwartz, o linguista Daniel Faïta e o sociólogo Bernard Vuillon, propondo a aproximação da academia ao mundo do trabalho, criou, em 1983, um estágio de formação continuada com trabalhadores da região de Provence na França. Essa experiência está na base da formação do grupo APST (Analyse Pluridisciplinaire des Situations du Travail) na Université de
Provence. 
textos mais ou menos escritos que enquadram, antecipam o agir real, o que eu chamo de primeira antecipação. Mas, se aceitarmos a ideia de que há sempre renormalizações e que sempre as renormalizações se operam e se concebem com formas específicas de saberes, emergidas na aderência do presente e do aqui e agora, esses saberes ignorados pelos primeiros têm que enriquecer, têm que ter uma certa visibilidade para os primeiros. Isso indica um trabalho para os primeiros, os saberes das normalizações, por isso eu digo que no segundo polo há saberes que antecipam o trabalho dos primeiros, que têm que não aceitar, mas discutir e entender o porquê, assim como há saberes do segundo polo que conduzem a transformar o agir que os primeiros haviam previamente prescrito/antecipado. 0 problema é que não há uma simetria entre essas duas antecipações; a primeira antecipação tem uma legitimidade social, hierárquica, epistemológica, é aceita por todos, porque o saber conceitual tem uma legibilidade, uma nobreza. Mas não é o mesmo caso da segunda antecipação, não é o fato dos saberes e valores emergidos na aderência do agir, aqui e agora.

Quando não há simetria, há o que eu chamo de uma tendência permanente à usurpação. $O$ que é usurpação? É a crença de que os homens e mulheres podem agir mecanicamente sob subordinação das prescrições, dos saberes antecipados, das normas. Desde que as normas antecedentes são fundadas sobre saberes "científicos", é natural que o agir obedeça a essas normas. É uma usurpação, porque cria uma espécie de assimilação do agir humano, há uma espécie de mecânica, como se fosse possível contemplar o ser humano, às vezes, como algo mecânico, é uma usurpação do uso dos conceitos. É normal de fazer, de pensar uma experimentação científica e pensar como se a natureza tivesse que se processar segundo os protocolos concebidos, de uma maneira mecânica, isso é normal. É assim que a ciência pode avançar, ou seja, a partir de experimentações com protocolos, mas é uma usurpação do uso de conceitos conceber que os conceitos podem ter o mesmo uso quando se dirigem aos seres humanos. Por isso, a ideia essencial é de tentar resistir a toda postura de usurpação. Aqui é muito difícil, porque, de um lado, não quer dizer que não é preciso, que não há necessidade de normas antecedentes. Claro que não! Precisamos de normas para viver em conjunto, para trabalhar juntos, para a vida social, mas, entre a necessidade de normas para nos organizarmos, localizarmos, e o uso de normas que supõem mais ou menos uma subordinação das pessoas humanas como se fossem mecânicas, a distância não é fácil. Toda a maneira de governar o trabalho que cai do lado da usurpação cria crises, cria sofrimentos, cria mau uso das técnicas, cria problemas da produção social. Claro que não há solução simples, nunca há solução simples.

A título geral, é preciso restituir na governança do trabalho uma postura parcial de simetria entre pessoas humanas, sem demagogia, porque sempre há necessidade de normas. $\mathrm{O}$ que é preciso é lutar contra toda a postura de usurpação e criar uma dinâmica permanente de "usinagem" das normas antecedentes. Isso quer dizer que os que têm que fabricar as normas antecedentes têm que ter sempre uma vigilância sobre as normas recriadas na atividade, as dimensões coletivas do trabalho. Não significa recusar as normas antecedentes, mas retrabalhar, levando em conta a segunda antecipação, é o que tentamos fazer, por meio do que chamamos dos Grupos de Encontro do Trabalho. Por meio do diálogo, colocamos em visibilidade as renormalizações e as razões das renormalizações, os saberes ligados a essas renormalizações e, a partir daí, vemos como se poderiam transformar as normas antecedentes. A direção geral seria refutar a postura da usurpação. Isso significa que, atrás dessas renormalizações, há valores da vida social e política que são colocados em questão sem soluções anteriormente fixadas. Quer dizer, é preciso respeitar mais ou menos os dois sentidos das antecipações com o máximo de responsabilidade, mesmo que isso não seja fácil para ninguém, pois respeitar as duas antecipações, sem fazer 
desaparecer a necessidade de normas, de responsabilidade é um desafio. Por isso, é importante o diálogo, a colaboração, o respeito de cada um, levando em conta a necessidade também de respeitar um quadro maior. Sempre que uma pessoa tem que avaliar as competências, ela deve fazê-lo tendo em conta os vários ingredientes da competência. Desse modo, é necessário se instruir dos ingredientes de pouca visibilidade que são ligados às renormalizações. Por exemplo, quando temos que instituir indícios quantitativos para avaliar os resultados da atividade, como discutir coletivamente o seu conteúdo? Um cálculo, um indício é normal, mas como construí-lo tendo em conta a segunda antecipação? Para tanto, não se pode fixar sobre uma espécie de ditatura dos números. Temos que funcionar com os números, mas a ditadura é uma usurpação. Isso nos remete à postura dos 3 Polos, que está na pergunta seguinte.

3. Maria da Glória Corrêa di Fanti e Vanessa Fonseca Barbosa - Um dos conceitos-chave da abordagem ergológica é o Dispositivo Dinâmico de 3 Polos (DD3P). Como se caracteriza esse dispositivo e qual sua importância para as pesquisas de cunho ergológico?

Yves Schwartz - A noção de Dispositivo Dinâmico de 3 Polos que começamos a utilizar desde os anos 1993 é uma espécie de síntese da nossa postura ergológica, não é um método de pesquisa, não é uma ferramenta, é muito mais uma postura geral que se pode deduzir exatamente do que já falamos nas perguntas antecedentes. A origem desse dispositivo está nas seguintes perguntas: Como conhecer as realidades humanas, se as realidades humanas são o resultado da atividade humana e se a atividade humana é sempre, sob todas as formas, um debate de normas, cujo resultado são as renormalizações? Como, nessas condições, imaginar uma postura de conhecimento que não altera, não ignora essa definição do agir humano? Por isso esse dispositivo, que é muito característico da abordagem ergológica, é uma consequência do que já dissemos, quer dizer que podemos, aqui, encontrar de novo essa noção de dupla antecipação. 0 polo 1 desse dispositivo olha a antecipação 1, o polo 2 contempla a antecipação 2 e a ideia é de lutar para que, em qualquer situação do agir humano, para falar dele sem mutilá-lo, temos que dispor dessa postura de fazer dialogado, de escutar, de colocar em relação dialética esses dois polos. No entanto, não temos que esquecer o que evocamos na pergunta 2 , que é a simetria das duas antecipações, a qual não é evidente. Pode acontecer e acontece às vezes nas empresas e nas organizações, não sei dizer se cada vez mais, porque é difícil, mas a necessidade de trabalhar essas duas antecipações não tem nada de óbvio, por razões de poder, de propriedade, de hierarquia. Claro que, em sociedades que são pautadas pelo mercado, o que eu chamo de sociedades de mercado e de direito, há uma tendência geral a dar prioridade ao polo 1, o das normas antecedentes, dos mandamentos. $\mathrm{O}$ caminho do primeiro polo para o segundo sem o movimento inverso é a melhor maneira de mandar ou de obter objetivos filiados ao polo que tem o poder. Repito que não há somente essa necessidade para as normas antecedentes, mas o deslocamento das normas antecedentes ao lado da usurpação é sempre uma tendência em nossas sociedades.

Por isso insisto sobre o polo 3; já identificamos os polos 1 e 2, mas o polo 3 é aquele que indica as condições humanas e sociais de funcionamento correto do trabalho entre os dois polos. Há duas maneiras de definir esse terceiro polo, o polo dos valores epistemológicos e éticos. $\mathrm{O}$ que isso quer dizer? Quer dizer que nos remete à aceitação das formas específicas de cultura e incultura; quer dizer que, do lado dos que estão do polo 1, que podem ser pesquisadores, cientistas, quadros de lideranças das empresas ou professores, há que se reconhecer o valor desses saberes; mas, ao mesmo tempo, há que se reconhecer o valor na dimensão operacional dos saberes do 
lado da segunda antecipação. Há uma necessidade de que cada um reconheça o valor relativo do outro polo e reconheça também valores éticos, porque há uma espécie de ética da pesquisa, de um lado, o que é normal, dá rigor à investigação porque há paixão da verdade; se, de outro lado, os saberes da segunda antecipação são saberes-valores, tal como eu desenvolvo essa noção no artigo indicado na questão 1 - Production de savoirs sur l'activité: quels nœuds entre Epistémologie et Ethique, da Revista Ergologia, número 14 - também há necessidade de reconhecimento mútuo de relação diferente com o mundo de valores. Em cada lado há valores operantes. Essa é a primeira definição do polo 3 . E a segunda definição, que também é muito importante, é que se trata de um polo do mundo comum a ser construído. O que isso significa? Significa pensar sobre que condição as pessoas vão aceitar trabalhar juntas. E essa questão é muito acentuada nas empresas. Com essa noção de assimetria, da qual já falei, se não há um respeito mútuo, se não há exigência comum de que o trabalho tem como objetivo tentar construir no mundo comum (como um mundo global, um mundo que pode ser o mundo da situação de um escritório, de um serviço, de uma empresa, de uma associação), a ideia é a de que cada um tem que fazer um esforço de consentir um intercâmbio, porque os dois têm interesse de construir um aprimoramento da situação comum. Se isso não é possível, é muito difícil, sobretudo nas empresas, esse dispositivo funcionar. E, para finalizar essa questão, me parece importante destacar também que esse dispositivo, o do terceiro polo, supõe o fato de repelir a tendência à usurpação; embora não seja um método, é um ponto de partida, uma postura que apela à criação de métodos para dar visibilidade à atividade humana.

3.1 0 polo 1 deve integrar esse polo e o polo 2 deve integrar essa postura de diálogo? De uma certa forma, o polo 3 deve ser integrado, incorporado dentro de cada um dos outros dois polos, é isso?
Yves Schwartz - Exatamente, integrado nesses dois polos que são socialmente bem diferentes. E, para concluir, esse terceiro polo tem que ser ao início do trabalho comum, porque, sem essa disposição, sem essa postura, ele não pode existir, não pode dar certo. Ele tem que ser integrado ao trabalho; o terceiro polo é o objetivo final do polo do mundo comum a ser construído, inserido no início e ao final.

4. Maria da Glória Corrêa di Fanti e Vanessa Fonseca Barbosa - No artigo de sua autoria Motivações do conceito de corpo-si: corpo-si, atividade, experiência, publicado em 2014 na Revista Letras de Hoje, o senhor afirma que "essa entidade que chamamos corpo-si transgride todas as fronteiras entre o biológico e o histórico" (p. 264) e menciona uma tríplice ancoragem para melhor compreender o conceito: biológica, histórica e singular. Como se dá essa inserção da singularidade no conceito e de que modo ela deve ser considerada pela Ergologia?

Yves Schwartz - Essa entidade corpo-si vem de um artigo de 1987 que foi traduzido em português, intitulado Trabalho e uso de si, na revista Proposições, volume 11, número 2, no ano de 2000, na Universidade Estadual de Campinas (UNICAMP). Digo isso porque essa referência à tríplice ancoragem é mais ou menos explicada no artigo dessa revista que pode ser consultado, o qual foi muito lido no Brasil sobre o trabalho e uso de si. Procurei explicar, nesse artigo, que tentei defrontar-me com essa potência de renormalização, essa entidade que renormalizava. Nesse artigo, me pareceu que havia três dimensões a ser contempladas para melhor entender essa entidade enigmática, tanto enigmática, que falei de si e não de sujeito. Temos que considerar a dimensão biológica, que é uma herança da filosofia de Georges Canguilhem, o que quer dizer que há uma dimensão genérica que não é a especificidade da humanidade, que nasce do fato de viver e uma 
tentativa de viver em saúde em sua relação com o meio. A polarização do meio pode ocorrer segundo valores positivos, que aprimoram a saúde, e valores negativos, que alteram a saúde; viver é sempre esse movimento de polarização. Quando falamos do viver humano, o meio não é somente o meio ecológico, mas é o meio histórico, social completamente saturado de normas. As normas não são coisas naturais, da natureza, são coisas instituídas através da história do gênero humano. Esse esforço de viver se especifica frente a cada meio histórico que nunca é um meio estandardizado, nunca é o mesmo. No Brasil, o meio de viver no Rio Grande do Sul não é o mesmo meio de viver em São Paulo ou no Nordeste. É sempre o meio histórico atravessado de sinais históricos. Essa procura de saúde dos seres humanos no meio histórico se faz sempre através de uma história psíquica e singular.

A questão me pergunta da inserção da singularidade. É uma questão difícil e muito instigante na qual tenho trabalhado muito agora. Cada momento de nossa vida é uma sequência de renormalizações e cada um de nós renormaliza por parte, levando em conta as características da situação que é mais ou menos geral para um grupo e levando em conta também a nossa maneira de conceber a saúde e a nossa relação com o mundo de valor. Isso nunca é estandardizado por ninguém. Frequentemente, evoquei esse exemplo da operadora da fábrica Thompson que toda pessoa interessada um pouco pela Ergologia já conhece. Claro que a renormalização dessa pessoa, dos gestos em um ganho de tempo, que reduz o tempo e o espaço, tem dimensões relativas a sua própria história, ao seu corpo histórico, o corpo que é mais ou menos fabricado por meio de sua história, suas habilidades, suas fraquezas e também de sua morfologia e suas relações com as colegas e consigo mesma, com certo mundo dos valores. Já falei muitas vezes que outra operadora terá outra renormalização, não tão diferente, mas um pouco outra, porque a história própria da pessoa pesa sobre as características da renormalização. Sobre a inserção da singularidade em si, acho que podemos dizer que o nosso corpo-si é a história integral de tudo isso, a história de toda a sequência de nossas renormalizações. 0 nosso corpo-si é uma espécie de sedimentação de nossas renormalizações que, a cada nova renormalização, mesmo que seja infinitesimalmente, reconfigura, (re)transforma um pouco esse corpo-si.

A singularidade de nosso corpo-si é sempre uma história contínua a sua própria história e uma figura de singularidade, desde que cada renormalização tenha uma dimensão singular, um corpo-si que é a sedimentação de todas as renormalizações como uma figura de singularidade. Claro que cada um vai enfrentar a vida com a sua maneira própria, aqui vem, por exemplo, a dimensão psicanalítica, como se constitui um pequeno ser humano por meio de sua família, como se constitui por meio da linguagem que nunca pode exprimir essa singularidade; a sua relação com a linguagem exprime a dificuldade dessa história. Toda essa história também tem implicação em seu corpo biológico, em suas maneiras de sintetizar, com o seu aparato neurológico. Há muitas dimensões psicanalíticas, neurológicas, psicológicas que intervêm para singularizar cada uma das renormalizações, e a história de todas as renormalizações acumuladas no corpo-si é precisamente a inserção da singularidade.

Depois de se colocar essa questão importantíssima, pode-se voltar à questão 2 para afirmar que a transformação da atividade de trabalho nunca pode ser uma história puramente singular, é uma história coletiva. Todavia, uma vez confirmada essa inserção da singularidade, coloca-se a questão da socialização das renormalizações, pois, para implementar as renormalizações, tem que ter um certo valor para um grupo, mais de um grupo, para um país, por exemplo; não pode ser unicamente a expressão da singularidade absoluta. Por isso, a transformação pode ser um dos papéis dos Grupos de Encontro do Trabalho, como dialogar, estabelecer compromissos para socializar as renormalizações. As dimensões singularizadas demais das renormalizações 
me parece que são um problema atual, porque as situações de trabalho há 50 anos eram muito parecidas. Por exemplo, a figura da fábrica com dois, três, quatro mil operários com postos de trabalho muito similares como uma vida social, com uma identidade, o fato de viver em bairros coletivos etc., em tudo isso havia uma relativa generalidade das normas a discutir, a retrabalhar, por isso as renormalizações tinham aspectos inicialmente transversais. Hoje, não é o caso. O mundo social e o mundo do trabalho são muito diversos, porque a socialização é uma coisa bem complicada.

\subsection{Há um maior individualismo?}

Yves Schwartz - Sim, a noção de individualismo faz parte dessa situação que torna a política uma coisa difícil para criar consensos a partir de debate de normas muito diferentes.

5. Maria da Glória Corrêa di Fanti e Vanessa Fonseca Barbosa - Tendo em vista que uma das maiores dificuldades das pesquisas em ciências humanas é o desenvolvimento de metodologias capazes de alcançar o ser humano em sua complexidade, quais os principais preceitos metodológicos que devem ser considerados em uma abordagem ergológica?

Yves Schwartz - Essa pergunta coloca-se ao lado dos problemas metodológicos bem clássicos. Cada vez que propomos uma pesquisa na área das ciências humanas, somos obrigados a detalhar nossos métodos. Não concordo muito com essa postura de colocar uma questão teórica e colocar, depois, os métodos adequados. Se a abordagem ergológica for uma postura antropológica, não pode dar métodos gerais. Gostaria de recusar o que chamo "o fantasma da onipotência". A onipotência - que é o fantasma que nos conduziria a dispor de métodos capazes de descrever, de entender o comportamento de nossos semelhantes independentemente da situação concreta - pode ser uma maneira de usurpação. Quer dizer que sabemos como encerrar o comportamento porque, com tal maneira de interrogar, de filmar, de registrar, de observar mecanicamente, poderíamos obter uma visão, uma interpretação dos comportamentos. Isso não é compatível com a ideia de atividade como debate de normas e do fato que cada renormalização traz uma dimensão inédita no mundo, que nunca pode ser antecipada a partir de métodos estandardizados. Por isso, esse fantasma pode ser uma espécie de usurpação. Já expliquei um pouco essa ideia em um texto na Letras de Hoje, número 50, de dezembro de 2015, com um artigo sobre o título L'activité peut-elle être objet d'"analyse"? escrito em francês. Essa ideia que desenvolvo pode ser lida nas páginas 50 e 51 . Podemos pensar na ideia de que a atividade humana como potência de renormalização permanente, de criação permanente de inéditos, não pode ser encerrada por instrumentos/ferramentas estandardizadas, mas, como já falamos na pergunta anterior, a matriz de todo o método é o Dispositivo com 3 Polos. De qualquer forma, nunca será possível apropriar-se totalmente da atividade dos nossos semelhantes, porque não podemos nos apropriar da vida mesmo. Na situação de trabalho, o que podemos é fazer emergir a atividade a partir da confrontação com as normas do trabalho social. $\mathrm{O}$ trabalho social, o trabalho mercantil é, na nossa sociedade, cheio de normas, prescrições, vulgarizações, objetivos quantificados. Segundo o que pensamos da atividade humana, é importante para resistir à postura de usurpação, fazer emergir o retrabalho dessas normas. Isso é muito importante, se não queremos gerir ou produzir crises e sofrimentos, ignorando a complexidade do trabalho. Tomar o trabalho como execução de normas não pode criar bons resultados humanos. Para evitar isso, dispomos de vários métodos, hoje bem experimentados. 
Possivelmente, os que trabalham sobre o trabalho já desenvolvem ou desenvolveram, por exemplo, o método do sósia, filmes, registros, gravações, observações, etc. Há muitos métodos para considerar a complexidade do trabalho, mas, para que esses métodos não sejam manipulações, eles têm que ser desenvolvidos com a postura do Dispositivo dos 3 Polos. Isso significa que, atrás de expressões como "o real da atividade", a atividade não é somente o que fazemos, mas também o que queríamos fazer. É melhor falar sobre debate de normas, porque dessimplificar o trabalho quer dizer fazer emergir problemas filosóficos, epistemológicas e problemas éticos e políticos, é o que quer dizer o terceiro polo do DD3P. Devemos dessimplificar o trabalho, porque, por meio do trabalho, temos que dar visibilidade a esses saberes-valores da segunda antecipação que têm que trabalhar com os saberes-valores da primeira. Temos que dessimplificar o trabalho não somente para melhorar um pouco um dispositivo, um momento da vida industriosa, mas também porque tratar do trabalho como algo simples prejudica o reconhecimento de novas ideias, de sugestões para um novo mundo a ser construído. É possível falar de debate de normas, por meio da dessimplificação do trabalho, com diferentes métodos; cada um tem um certo valor. No entanto, o mais importante não é o método, mas dar espaço ao trabalhador, via esses métodos, no que se refere a como gerir o seu trabalho, como trabalhar em comum, como viver em comum. Esse espaço também pode auxiliar a decidir como vamos nos organizar, como vamos produzir, como vamos abordar o usuário.

A postura do Dispositivo de 3 Polos tem que ser de abertura aos valores de vida, de maneira mais ou menos visível, os quais são constituídos pelas renormalizações. Nesse sentido, há uma palavra que ainda não usei que é "reservas de alternativas". Cada renormalização é uma reserva de alternativas, uma maneira de propor algo para fazê-lo melhor. Essa reserva de alternativas tem que ser socializada para dar argumentos a uma transformação de tal dimensão do trabalho em comum, mas, atrás dessas reservas de alternativas, não há dimensão de um corpus de novas normas todas formadas e a serem seguidas por todas as partes envolvidas. "Reservas" não quer dizer que se tratem de soluções novas a levarem em conta, como se fossem obrigatoriamente as melhores, pode haver renormalizações discutíveis, perigosas. A socialização é um debate para conceber a transformação do mundo em viver, segundo as várias circunscrições ou definições do mundo ou do meio considerado na situação. Por isso, o DD3P é a postura matriz que legitima vários métodos sob a condição de que incorporem tudo o que inclui a noção de debate de normas, a dessimplificação do trabalho, conforme faziam os ergonomistas com crônicas da atividade ou filmes ou métodos aos sósias, que teriam como consequências fazer emergir a segunda antecipação aos responsáveis da primeira. Por exemplo, você não pode usar métodos de instrução aos sósias sem aceitar essa consequência que os dados originados nesse método perturbam mais ou menos a maneira de governar, antecipar ou conceber o trabalho dos outros. Por isso, a postura do DD3P é a matriz de muitos métodos válidos, sempre considerando o terceiro polo.

\section{Maria da Glória Corrêa di Fanti e Vanessa Fonseca Barbosa -} Considerando a Ergologia como uma ciência pluridisciplinar que conta com saberes advindos de diferentes áreas do conhecimento na sua constituição, gostaríamos de que nos falasse sobre como vislumbra a contribuição dos linguistas em e para os estudos da Ergologia.

Yves Schwartz - O primeiro ponto é dizer que a Ergologia não se define como uma ciência pluridisciplinar, isso é uma questão complicada; nunca a definimos como uma disciplina científica. Mas o que é a Ergologia? Adotamos o termo, ou a expressão, em português, abordagem como uma maneira de afirmar que não é uma nova disciplina, é uma postura, uma abordagem 
que requer outras, todas outras disciplinas, notadamente as das Ciências Humanas, sempre em uma situação de discussão com elas, às vezes de crítica, numa dimensão de uso e de polêmica com essas disciplinas. Alguns pensam que é uma disciplina, uma ciência, que é filosofia, por exemplo. Prefiro falar de abordagem. $\mathrm{O}$ que é verdade na sua pergunta é que a Ergologia tem necessidade de interface com outras disciplinas das Ciências Humanas e, notadamente, das Ciências da Linguagem. Por quê? Quando, há 33 anos, iniciamos a nossa experiência de trabalho sobre o trabalho com trabalhadores na Universidade de Provence, cuja maioria não tinha formação acadêmica, sentimos um grande desafio que estava relacionado a saber como discutir com eles, porque o nosso uso da linguagem era o uso do polo 1 do DD3P, o uso de conceitos em desaderência e sabíamos, por uma espécie de intuição, que não era exatamente a mesma maneira dos trabalhadores usarem a linguagem especialmente em situação de trabalho. Essa questão era um grande problema sobre o qual discutimos com o meu colega e amigo Daniel Faïta, que é precisamente linguista. Havia uma dimensão da linguagem que era clara demais: o trabalho nas nossas sociedades, que são fundadas sobre o direito, a prescrição, as normas, é apoiado sobre a linguagem que se pode escrever, que se pode formalizar. No entanto, a nossa intenção no início era traduzir o trabalho, tornar acessível aos trabalhadores o que era pensado pelos outros através de normas, prescrições e tudo isso. Nesse cenário, havia algumas questões: $\mathrm{O}$ mundo do trabalho fala muito, as pessoas falam muito entre elas. Então, como poderia se caracterizar essa linguagem, na medida em que não podia ser exatamente a linguagem do polo 1, das prescrições, do escrito? Como falar com os trabalhadores, como falar do trabalho fora do trabalho? Em qual meio criar esse diálogo dos polos, do DD3P, com usos diferentes da linguagem? Na medida em que aprofundávamos os conceitos ergológicos, essa questão da linguagem no e do trabalho se complicava.
Se a atividade humana é sempre um debate de normas, entre normas mais ou menos codificadas, prescritas, e normas nascentes, não necessariamente bem formuladas, se a atividade é sempre o lugar de renormalizações, é sempre uma peça de inédito no mundo, apesar de ser minúsculo, se a atividade é o lugar de reservas de alternativas, como exprimir essas reservas que são sempre misturas de gestos, de pensamentos e de palavras? Se a atividade é implementação de competências e se as competências forem uma síntese de ingredientes diferentes, com relações diferentes ao escrito, ao formalizado e, também, se a atividade é ancorada no corpo-si como um indício dos debates de normas, o corpo-si é uma mistura de biológico, intelectual, de cérebro etc. Claro que essa dimensão da linguagem enquanto diferente da linguagem prescrita, da linguagem escrita é uma questão central e muito difícil, por isso expliquei um pouco essa necessidade de interface no artigo Abordagem ergológica e necessidade de interfaces pluridisciplinares, em um número especial da revista Revel, em homenagem à nossa colega tão querida, Marlene Teixeira, que muito nos ajudou a alargar essa questão. Para responder a essa pergunta, o melhor é nos remetermos a esse artigo. No entanto, para tentar resumir, direi que, para auxiliar nessa nossa séria dificuldade, precisamos dos linguistas, mas não de todas as linguísticas, e sim de cooperações com os grupos que encontramos particularmente no Brasil, como as professoras Maria Cecília de Souza-e-Silva e Maria da Glória Corrêa di Fanti, entre outros, que trabalham com linguistas do enunciado, da enunciação, focalizando o uso da linguagem vinculado ao momento da atividade, ao agir no presente, aqui e agora, no momento do viver e do trabalhar. Todos esses linguistas - que falavam, como Bakhtin, da dimensão irrepetível do ato, e como Benveniste, que a linguagem na mente de todos servia para viver - ajudaram-nos a pensar sobre o que era inédito na situação de trabalho, dando um grande apoio aos estudos ergológicos. Talvez seja interessante aprofundar essa dimensão das relações entre o falar e o corpo-si, sabendo que o corpo-si, através de seus 
debates de normas, é atravessado pelo o que eu chamo de mundo de valores. Esse debate nunca é evidente, sempre tem uma dimensão inédita, nunca é mecânico, implica não só a saúde mas todas as dimensões do corpo-si. Falar é uma maneira de dialogar com o seu corpo-si frente a uma situação que sempre é, por uma parte, inédita, e essa dimensão da linguagem dentro do corpo-si, que é o cruzamento dos debates de normas, me parece ser uma dimensão de pesquisa a ser aprofundada com o apoio dos linguistas que insistiram sobre essa dimensão vital da enunciação.

7. Maria da Glória Corrêa di Fanti e Vanessa Fonseca Barbosa - Por fim, gostaríamos de que nos falasse sobre o seu olhar para os estudos da Ergologia no Brasil. Como observa os trabalhos desenvolvidos aqui e como os compreende, se comparados às pesquisas realizadas, por exemplo, na França?

Yves Schwartz - O descobrimento do Brasil - para nós da Ergologia era um pouco o descobrimento (risos) - foi uma grande sorte ao desenvolvimento da abordagem ergológica, porque, na França, tivemos muitas dificuldades para desenvolver essa abordagem, pois ela é, por natureza, transdisciplinar. Isso significa que não podemos ficar em um setor único do saber, uma vez que, se o trabalhar é uma dimensão histórica do agir no geral, isso traz com ele todas as dimensões da vida humana, é uma visão antropológica. Essa dimensão transdisciplinar, essa necessidade de os dispositivos, o DD3P, essa necessidade de sempre se instruir dos interlocutores da vida social e do trabalho, essas exigências são desprezadas/mal compreendidas no meio universitário, e essas dificuldades não eram as mesmas quando descobrimos, pouco a pouco, vários amigos, vários pesquisadores e pesquisadoras em várias cidades do Brasil. Uma questão que não podemos exagerar, mas que existe no Brasil, é uma abertura às dimensões transdisciplinares. Era o trunfo e os defeitos da monodisciplina. Na França, adquirimos formações muito substanciais, de qualidade, mas é muito difícil criar equipes pluridisciplinares, essa ideia não se desenvolve na carreira da universidade francesa. A vantagem de se trabalhar com os amigos, colegas brasileiros, é essa abertura. Por exemplo, ao se tentar hoje escrever um novo livro sobre o que é um pouco o retorno ao conceito do uso de si, a maneira de ver, de contemplar esse conceito através de leitores, de pesquisadores brasileiros, é possível transitar entre conceitos mais ou menos filosóficos no campo do trabalho ou em outros campos, como na psicanálise. Não há dificuldade de fazer essas travessias. Assim, os linguistas podem se interessar pela ergonomia e aprofundar a sua reflexão com uma visão muito mais rica do trabalho do que habitualmente os seus colegas.

A lista dos setores, dos lugares, dos departamentos onde fui convidado no Brasil é bem surpreendente: fui convidado, por exemplo, no Departamento de Educação da Universidade Estadual de Campinas (UNICAMP) e da Universidade Federal de Minas Gerais (UFMG); nos Departamentos de Filosofia e Ciências Humanas, Departamento de Engenharia de Produção também na UFMG; fui convidado em Departamentos de Psicologia e de Psicologia do Trabalho na Universidade Federal do Rio de Janeiro (UFRJ) e na Universidade Federal do Espírito Santo (UFES); no Departamento de Ergonomia na Universidade Federal da Paraíba (UFPB) e na Universidade Federal Fluminense (UFF); fui convidado no Departamento de Administração e Gestão, na Universidade Federal de Pernambuco; nos Centros Técnicos, como CEFET, em Vitória, Curitiba, e Belo Horizonte; fui convidado também nos Departamentos de Ciências da Linguagem, na PUC de São Paulo e na PUC do Rio Grande do Sul; no Departamento de Administração e Comunicação, na Universidade de São Paulo. Bom, para resumir, os colegas do Brasil foram bem sensíveis a esse apelo de todos os saberes disponíveis sob condição de retrabalhá-los com os conceitos ergológicos e cada vez que venho ao Brasil, 
para nós da Ergologia, e para mim particularmente, é uma oportunidade de aprofundar a interface entre os conceitos ergológicos e a interdisciplinaridade, com as ciências da linguagem, a educação, a psicologia, a administração etc. Um exemplo dessa interface, dentre muitos outros, é o de uma colega que fez o seu pós-doutorado na Universidade de Provence e trabalha com o uso de simuladores na condução de veículos utilitários. A cooperação com a Ergologia lhe permitiu circunscrever melhor as dimensões úteis na aprendizagem, mas também os limites da simulação, já que simular uma situação é sempre também uma maneira de estandardizá-la. Ela escreveu um artigo muito interessante e me pediu para escrever com ela e cada vez que isso acontece é para mim uma ocasião de aprofundar as reflexões da Ergologia. Outro exemplo de interdisciplinaridade e parceria com o Brasil é um trabalho através da psicanálise. Eu conheci um jovem psicanalista de Belo Horizonte, Admardo Gomes Júnior (2013), que estava fazendo uma tese sob orientação da professora Daisy Cunha, que trabalha no setor das Ciências da Educação na UFMG. A pesquisa, para nós, já seria uma transgressão de disciplina, ao fazer uma analogia entre a noção de sintoma de Lacan, no fim de sua vida, e de saber fazer com seu sintoma e uso de si por si. Para mim, é uma oportunidade de aprofundar uma dimensão que há muito tempo era insuficiente das relações entre Psicanálise e Ergologia. Essa abertura é uma maneira de ampliar as reflexões da Ergologia em novos setores, novos conceitos, novas disciplinas, não inteiramente novas para nós, mas a cooperação aprofundou a nossa reflexão e por isso a nossa relação com o Brasil é bem rica e favorável para o desenvolvimento da abordagem ergológica.

\section{Referências}

BARBOSA, V. F. Uma voz apagada? Análise da atividade de revisão de textos acadêmicos sob as perspectivas bakhtiniana e ergológica. Projeto de Doutorado. Pontifícia Universidade Católica do Rio Grande do Sul, Porto Alegre, 2014.
DI FANTI, M. G. C. Perspectiva dialógica e abordagem ergológica: questões de linguagem e trabalho. Projeto de Pesquisa. Pontifícia Universidade Católica do Rio Grande do Sul Porto Alegre, 2014a.

A tensa relação com o discurso do outro e a produção de sentidos: contribuições bakhtinianas para a pesquisa e a formação na contemporaneidade. Projeto de Pesquisa Edital Pesquisador Gaúcho (2014-2016), Fundação de Amparo à Pesquisa do Rio Grande do Sul (FAPERGS), 2014b.

Linguagem e trabalho: diálogos entre estudos discursivos e ergológicos. In: DI FANTI, Maria da Glória Corrêa; SOUZA-E-SILVA, Maria Cecília de; SCHWARTZ, Yves. Letras de Hoje, Porto Alegre, v. 49, n. 3, p. 253-258, 2014c. http://dx.doi.org/10.15448/19847726.2014.3.19111

GOMES JÚNIOR, A. B. O uso de si e o saber fazer com o sintoma do trabalho. 2013. $231 \mathrm{fls}$. Tese (Doutorado em Educação) - Universidade Federal de Minas Gerais, Belo Horizonte, 2013.

SCHWARTZ, Y. Abordagem ergológica e necessidade de interfaces pluridisciplinares. Trad. Maria da Glória Corrêa di Fanti. ReVEL, ed. esp., n. 11, p. 253-264, 2016.

L'activité peut-elle être objet d' "analyse"? In: DI FANTI, Maria da Glória Corrêa et al. Letras de Hoje, Porto Alegre, v. 50, n. esp., p. 42-52, 2015a. http://dx.doi. org/10.15448/1984-7726.2015.s.23138

Production de savoirs sur l'activité: quels nœuds entre Epistémologie et Ethique? In: Revista Ergologia, v. 1, n. 14, p. 117-129, 2015 b.

. Motivações do conceito de corpo-si: corpo-si, atividade, experiência. In: DI FANTI, Maria da Glória Corrêa; SOUZA-E-SILVA, Maria Cecília de; SCHWARTZ, Yves. Letras de Hoje, Porto Alegre, v. 49, n. 3, 2014, p. 259-274. http://dx.doi.org/10.15448/19847726.2014.3.19102

. Trabalho e uso de si. Trad. Maria Lúcia da Rocha Leão e Maria Inês Rosa. In: Revista Proposições, v. 11, n. 2, p. 34-50, 2000.

SCHWARTZ, Y.; DUC, M.; DURRIVE, L. Trabalho e Ergologia. In: SCHWARTZ, Y.; DURRIVE, L. (Org.). Trabalho \& Ergologia: conversas sobre a atividade humana. 2. ed. Niterói: EdUFF, 2010. p. 25-36. 